\title{
Seismic attenuation structure in central Mexico: Image of a focused high-attenuation zone in the mantle wedge
}

\author{
Ting Chen ${ }^{1}$ and Robert W. Clayton ${ }^{1}$ \\ Received 29 July 2008; revised 19 February 2009; accepted 21 April 2009; published 14 July 2009.
}

[1] Velocity spectra from moderate-sized earthquakes were used to investigate the $\mathrm{P}$ wave attenuation structure in central Mexico. In particular, we included regional events with magnitudes in the range of 4.5 to 6.1 recorded from 2005 to 2007 on the Middle American Subduction Experiment (MASE) array, which consists of 100 broadband sensors across central Mexico from Acapulco to Tempoal, near the Gulf of Mexico. By assuming a Brune-type source, a frequency-independent $t^{*}$ value was obtained for each seismogram in the frequency band 1 to $30 \mathrm{~Hz}$. These measurements were then inverted for twodimensional spatial variations in $Q_{p}$ in the cross section along the MASE array, perpendicular to the trench. The model has uniform $20 \mathrm{~km}$ vertical grid spacing down to a depth of $200 \mathrm{~km}$ and $50 \mathrm{~km}$ or $100 \mathrm{~km}$ horizontal grid spacing depending on ray coverage. The inversion results show low attenuation in the subducting slab and high attenuation in the mantle wedge and the crust below and to the north of the volcanic belt. The focused high-attenuation zone $\left(Q_{p}<200\right)$ in the mantle wedge lies away from the top of the slab, between depths of $80 \mathrm{~km}$ and $120 \mathrm{~km}$ beneath the volcanic belt, and is likely to be related to relatively high temperature, fluids, and partial melts produced in subduction process. The high-attenuation region in the lower crust correlates with the low-resistivity and low-velocity region and could be caused by partial melts and fluids from dehydration and magmatic processes.

Citation: Chen, T., and R. W. Clayton (2009), Seismic attenuation structure in central Mexico: Image of a focused high-attenuation zone in the mantle wedge, J. Geophys. Res., 114, B07304, doi:10.1029/2008JB005964.

\section{Introduction}

[2] Intrinsic attenuation is energy loss or absorption as seismic waves pass through the rocks. One of the major mechanisms of intrinsic attenuation is the frictional loss in dry rocks due to relative movement at grain boundary, which is strongly dependent on pressure and temperature [Jackson et al., 1992]. Another one is viscous damping when there is fluid present [Mavko, 1980]. In recent years, detailed images of the attenuation structure have been obtained in different subduction zones such as Tonga-Fiji [Roth et al., 1999], Japan [Tsumura et al., 2000], central Andes [Schurr et al., 2003], Alaska [Stachnik et al., 2004], New Zealand [Eberhart-Phillips et al., 2008], Costa Rica and Nicaragua [Rychert et al., 2008]. These studies generally show that the subducting slab is characterized by low attenuation, while high attenuation is found in the mantle wedge and/or the crust beneath the volcanic arc. Detailed attenuation images in the mantle wedge and the crust above, however, vary from place to place. In some places such as

\footnotetext{
${ }^{1}$ Seismological Laboratory, California Institute of Technology, Pasadena, California, USA.
}

Copyright 2009 by the American Geophysical Union. 0148-0227/09/2008JB005964\$09.00
Alaska, Costa Rica and Nicaragua [Stachnik et al., 2004; Rychert et al., 2008], the high attenuation is concentrated in zones within the mantle wedge. These obtained attenuation images help to determine the relative viscosity [Karato, 2003], and provide constrains on the mantle wedge temperature [Stachnik et al., 2004] and subduction dynamics including slab dehydration and melt transport [Schurr et al., 2003].

[3] The seismic attenuation in central Mexican subduction zone has been studied by several authors [e.g., Castro et al., 1990; Ordaz and Singh, 1992; García et al., 2004; Singh et al., 2006, 2007]. However, because seismicity in this region is sparse, especially for deep earthquakes, most of these studies are confined to the crust. Castro et al. [1990] estimated the average crust attenuation for shear waves propagating along the Pacific coast. Ordaz and Singh [1992] determined the average $Q_{s}$ in the crust including both coastal and inland paths. García et al. [2004] analyzed some intermediate-depth inslab earthquakes, and reported an average $Q_{s}$ similar to that by Ordaz and Singh [1992]. Singh et al. [2007] studied the $Q$ of $\operatorname{Lg}$ waves, and found that $Q$ in the central Mexican Volcanic Belt is lower than that in the fore arc. Because of the lack of seismic stations in the back arc, the attenuation of the mantle wedge in this region was only recently studied by Singh et al. [2006]. 


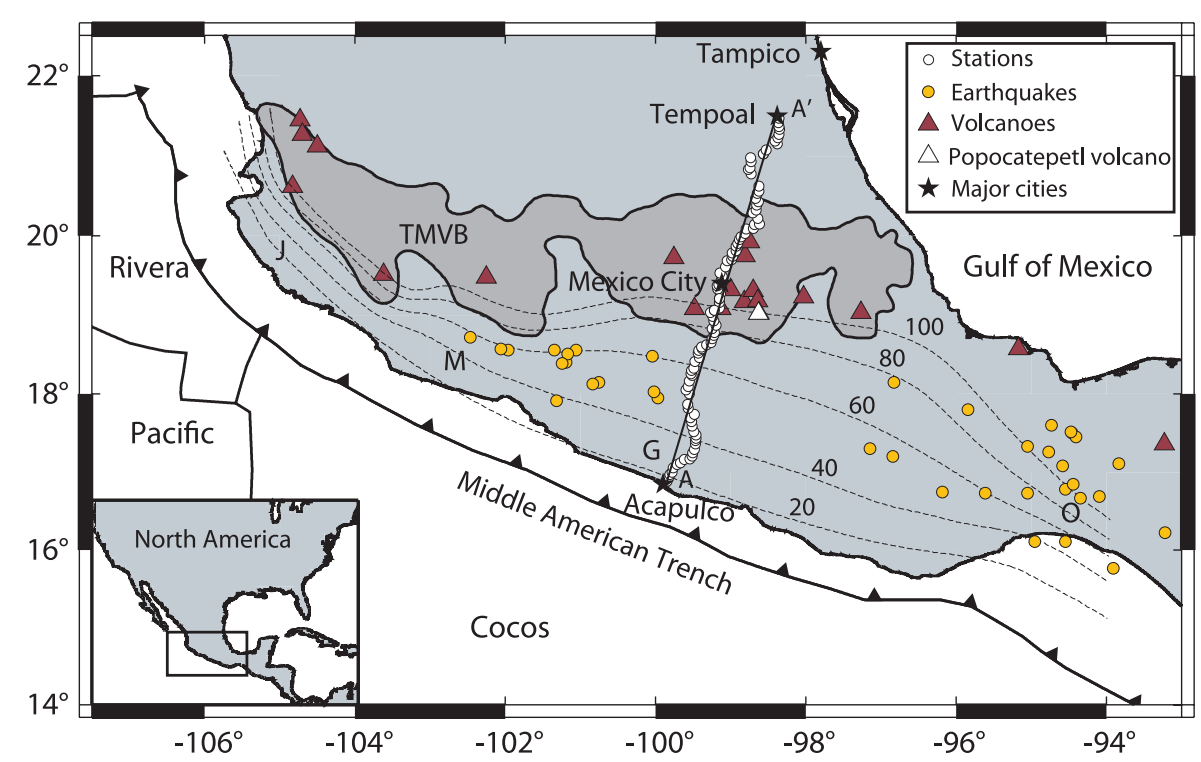

Figure 1. The stations and events used in this study. Open circles and solid circles indicate MASE array and epicenters of events used in this study, respectively. Solid triangles denote volcanoes, and the open triangle shows Popocatépetl volcano. The dark gray shaded area indicates the Trans-Mexican Volcanic Belt (TMVB). Slab isodepth contours from Pardo and Suárez [1995] are shown in dashed lines. J (Jalisco), M (Michoacan), G (Guerrero-Oaxaca), and O (southern Oaxaca) indicate four segments. Major cities along MASE array are shown as stars for reference. The line $\mathrm{AA}^{\prime}$ represents cross-section projection for 2-D attenuation tomography.

They analyzed shear waves from 16 earthquakes recorded at a station near the Gulf of Mexico, and found that waves passing through the mantle wedge attenuate more than those mostly traveling through the continental lithosphere. They suggested that this difference is due to the low $Q$ of the mantle wedge compared with the continental lithosphere, and estimated an upper bound of $120 f^{0.75}$ for shear wave $Q$ in the mantle wedge. A detailed image of the attenuation structure in central Mexico requires a much larger data set. The recent Middle American Subduction Experiment (MASE), which was a temporary deployment of 100 broadband stations in central Mexico from 2005 to 2007, provides us such an opportunity to obtain a two-dimensional attenuation structure in this region.

\section{Tectonic Setting}

[4] In the Mexican subduction zone, the Rivera and Cocos Plates are subducting beneath the North American Plate along the Middle American Trench with convergence rate increasing from $3.9 \mathrm{~cm} / \mathrm{a}$ at $106.5^{\circ} \mathrm{W}$ to $7.2 \mathrm{~cm} / \mathrm{a}$ at $94^{\circ} \mathrm{W}$ [DeMets et al., 1994]. The age of the oceanic crust at the trench also increases from about $10 \mathrm{Ma}$ in the west to $23 \mathrm{Ma}$ in the east [Pardo and Suárez, 1995]. Despite the generally monotonic increase in subduction rate and plate age toward the southeast, the slab dip shows anomalous behavior. Pardo and Suárez [1995] studied the lateral variations in the dip of the subducted oceanic plates by locating hypocenters of earthquakes, and found that a shallow subhorizontal slab in central Mexico is bounded by steeper slab geometry in both northern and southern Mexico. On the basis of the seismicity, focal mechanisms, and slab geometry, the Mexican subduction zone can be divided into four segments [Pardo and Suárez, 1995] (Figure 1): (1) the Jalisco segment, where the Rivera plate subducts at a steep angle $\left(\sim 50^{\circ}\right)$; (2) the Michoacan segment, where the dip angle of Cocos slab decreases gradually $\left(\sim 50^{\circ}-0^{\circ}\right)$; (3) the Guerrero-Oaxaca segment, where the slab is almost flat for about $250 \mathrm{~km}\left(\sim 0^{\circ}\right)$; and (4) the southern Oaxaca and Chiapas segment, where the dip angle of Cocos slab increases gradually $\left(\sim 0^{\circ}-30^{\circ}\right)$. Receiver functions and seismic velocity tomography studies from recent MASE in Guerrero region imaged the slab in detail in a cross section perpendicular to the Middle American Trench and through Mexico City [Pérez-Campos et al., 2008]. The results show that the Cocos slab is horizontal beneath the North American plate for about $250 \mathrm{~km}$, and then plunges into the mantle just before the volcanic belt with a dip angle of about 75 degrees. The slab is truncated at a depth of $500 \mathrm{~km}$ [Husker and Davis, 2009].

[5] Another interesting tectonic feature in central Mexico is the location of the Trans-Mexican Volcanic Belt (TMVB). Unlike the usual trench-parallel geometry in other subduction zones, the TMVB lies across central Mexico with an angle about $16^{\circ}$ oblique to the Middle American Trench. It is about $300 \mathrm{~km}$ away from the trench near Mexico City. The TMVB consists of nearly 8000 volcanic structures, and extends about $1000 \mathrm{~km}$ long while varies in width between $80 \mathrm{~km}$ and $230 \mathrm{~km}$ [Gómez-Tuena et al., 2007]. A variety of volcanic structures have been formed since the middle to late Miocene, including large stratovolcanoes, monogenetic cones, shield volcanoes, calderas, lava flows and domes [Macias, 2007]. Popocatépetl, one of the largest stratovolcanoes in Mexico, is located just $65 \mathrm{~km}$ southeast of Mexico 

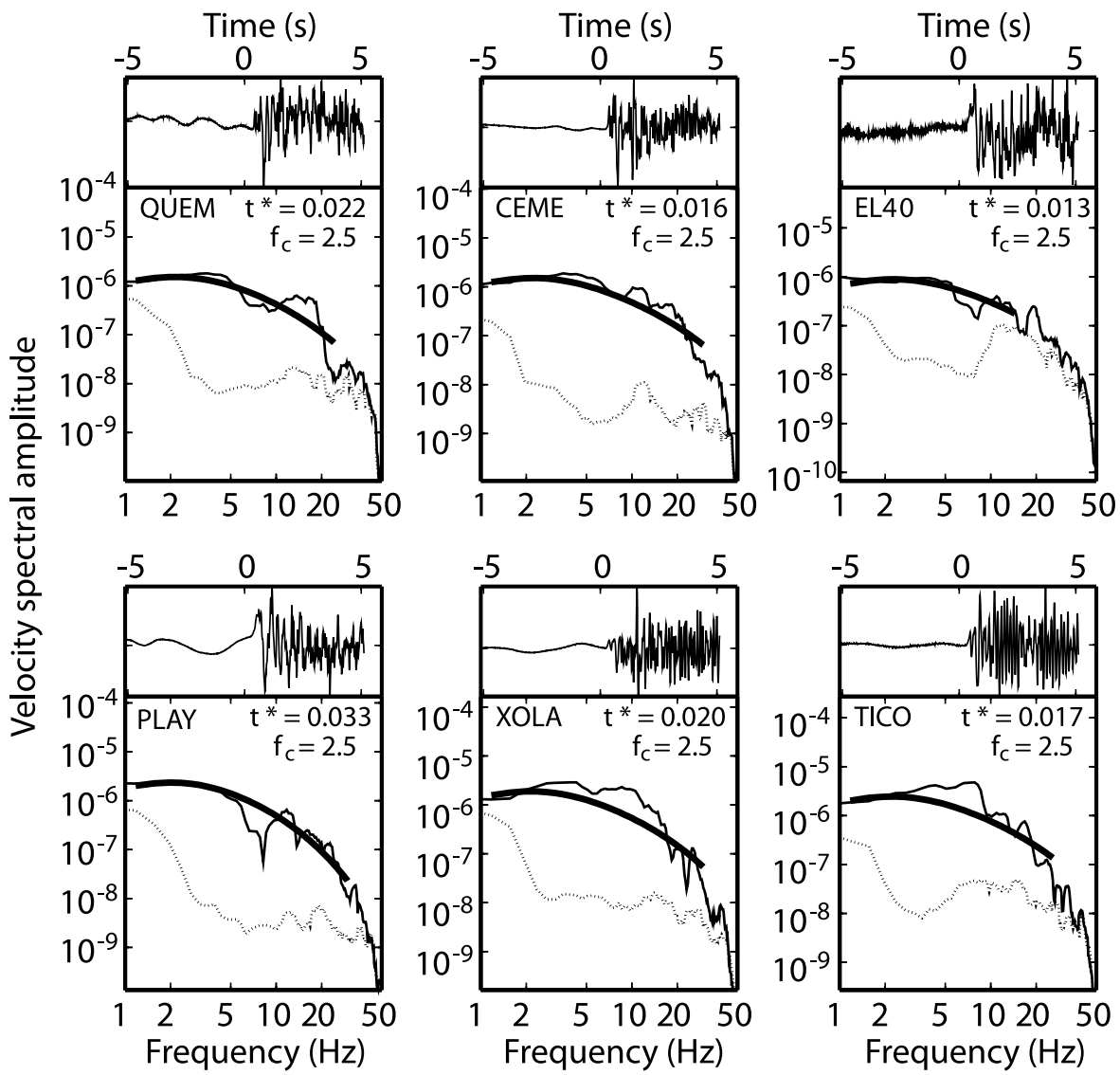

Figure 2. Examples of waveforms and fittings to the spectra of one earthquake (lat, $17.1^{\circ}$; lon, $-93.8^{\circ}$; depth, $184 \mathrm{~km} ; 22$ June 2005). For each station, the velocity spectra are shown below the waveform. Signal and noise spectra are calculated from $2.56 \mathrm{~s}$ windows after and before P arrivals and are shown as solid and dotted lines, respectively. Heavy lines indicate the fittings to the signal spectra over the frequency range with signal-to-noise ratio greater than 2. The station name and estimated values of $t^{*}$ and $f_{c}$ are shown for each station.

City, and has been active since 1994 after 67 year of quiescence [Macias, 2007]. Although some alkaline volcanism exists, the dominant volcanic sequences in the TMVB are calc-alkaline, and the volcanic belt is thought to be related to the subduction of the Rivera and Cocos plates [Pardo and Suárez, 1995].

\section{Data}

[6] The MASE survey line is perpendicular to the Middle American Trench, and runs across Mexico from Acapulco on the Pacific coast, through Mexico City, and to Tempoal near the Gulf of Mexico (Figure 1). It was in place from 2005 to 2007. The array consists of 100 three-component broadband sensors (Guralp CMG-3T) spaced approximately $5 \mathrm{~km}$ apart. The data are recorded continuously at 100 samples per second.

[7] In this study, we analyzed seismograms from 37 regional earthquakes recorded by MASE array. These events are within the magnitude range of 4.5 to 6.1 , and the depths vary from $50 \mathrm{~km}$ to $184 \mathrm{~km}$ (Figure 1). The locations of the events are determined by the Servicio Sismológico Nacional (SSN) of Mexico, which consists of 36 broadband stations and about 10 short-period stations through Mexico. The SEISAN program [Haskov and Ottemöller, 1999] is used by the SSN for location determination.

\section{Estimation of Path Attenuation}

[8] The attenuation of seismic waves can be estimated from the amplitude spectra. The Fourier velocity spectral amplitude of a body wave from event $j$, recorded at a hard rock site station $i$, can be written as [e.g., Anderson and Hough, 1984]

$$
A_{i j}(f)=C S_{j}(f) I_{i}(f) \exp \left(-\pi f t_{i j}^{*}\right),
$$

where $S(f)$ is the source spectrum, $I(f)$ is the instrument response, $C$ is the frequency-independent amplitude term associated with geometric spreading, radiation pattern, and other static effects. The exponential term describes the attenuation effect. The whole path attenuation operator $t^{*}$ can be expressed as $t^{*}=\tau / Q$, with $\tau$ being the total travel time and $Q$ being the average quality factor along the ray path. 

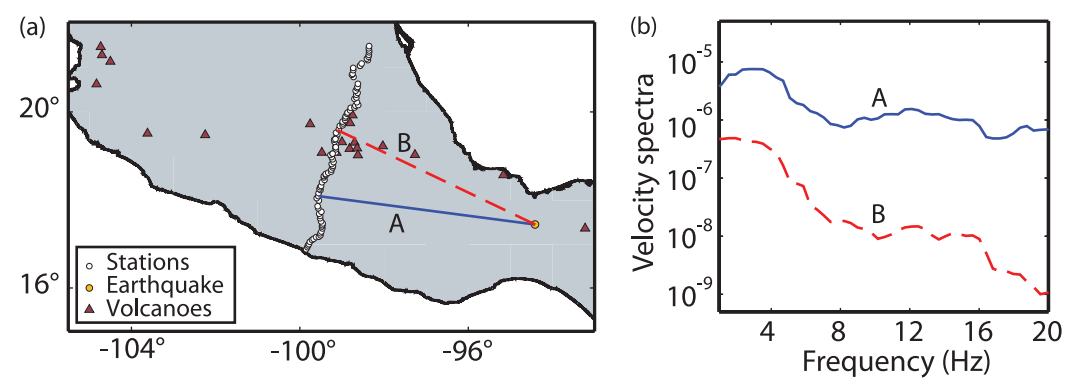

Figure 3. Example of attenuation contrast for two waves from the same event (lat, $17.5^{\circ}$; lon, $-94.4^{\circ}$; depth, $179 \mathrm{~km}$; 8 May 2006) and recorded at the stations along MASE array. (a) Path A and path B have about the same length. Path A goes through the fore arc, and path B goes through the arc and back arc. (b) The velocity spectra of $P$ waves along path $A$ and path $B$. The spectral amplitude of the wave along path $\mathrm{B}$ decays more rapidly with frequency than that of the wave along path $\mathrm{A}$, indicating that the average attenuation along path $\mathrm{B}$ is higher than that of path $\mathrm{A}$.

[9] Assuming a Brune-type source [Brune, 1970], the source velocity spectrum of event $j$, can be written as

$$
S_{j}(f)=\frac{f M_{0 j}}{1+\left(f / f_{c}\right)^{2}},
$$

where $M_{0 j}$ is the seismic moment, and $f_{c}$ is the corner frequency. Since only data in the flat portion of the pass band $(0.01-30 \mathrm{~Hz})$ of the recording system were used in this study, $I(f)$ in equation (1) can be neglected, leading to

$$
A_{i j}(f)=\frac{C^{\prime} f}{1+\left(f / f_{c}\right)^{2}} \exp \left(-\pi f_{i j}^{*}\right),
$$

where $C^{\prime}$ is a combination of $C$ from equation (1) and frequency-independent terms from $S(f)$ and $I(f)$.

[10] The iterative approach of Eberhart-Phillips and Chadwick [2002] was applied to determine frequencyindependent $t_{i j}^{*}$ for each ray path, together with $C^{\prime}$ for each ray and a common corner frequency $f_{c}$ for each event. The corner frequency $f_{c}$ is determined using a grid search over the frequency range $1-20 \mathrm{~Hz}$ using all available velocity spectra for each event. Then for each spectrum, up to 10 iterations of the loop in which $C^{\prime}$ and $t_{i j}^{*}$ are updated sequentially, are carried out starting with an initial estimate of $t_{i j}^{*}$. In the analysis of $\mathrm{P}$ waves, we used the high-sample rate vertical-component waveforms. The velocity amplitude spectra were calculated from a $2.56 \mathrm{~s}$ time window beginning at the $\mathrm{P}$ wave using a multitaper algorithm [Park et al., 1987]. Corresponding noise spectra were also calculated from a $2.56 \mathrm{~s}$ time window before the $\mathrm{P}$ wave. To ensure a high-quality estimate of $t^{*}$, we only used the data with a signal-to-noise ratio greater than 2 in a frequency bandwidth wider than $5 \mathrm{~Hz}$. The lower limit of the frequency band is $1 \mathrm{~Hz}$, and the upper limit varies from $6 \mathrm{~Hz}$ to $30 \mathrm{~Hz}$ depending on the noise. Examples of waveforms and fittings to the spectra are shown in Figure 2.

[11] On the basis of spectral analysis, we found that the waves passing through the arc and back arc have different attenuation features than the waves passing through the fore arc. Figure 3 shows an example of this attenuation contrast for two paths. Path A and path B are from the same event, and are chosen to have the same path length to eliminate the spectral difference due to geometric spreading. Path A goes through the fore arc, while path B goes through the arc and back arc. We calculated the spectra of the $\mathrm{P}$ waves traveling along the two paths, and found that the spectrum of the wave going along path $\mathrm{B}$ decays more rapidly with frequency than that of the wave going along path $\mathrm{A}$, which indicates higher attenuation along path $\mathrm{B}$ than path $\mathrm{A}$. The overall lower absolute spectral amplitude of wave B than that of wave A is partly due to the higher average attenuation along path $\mathrm{B}$, and partly due to other effects such as source radiation pattern, scattering and local site effects. In Figure 4 , we show the attenuation variation of waves from the same event and received at stations along the MASE array by plotting the value of the path-averaged attenuation parameter $1000 t^{*} / \tau$ for each ray, where $\tau$ is the travel time. It is clear that the waves passing through the arc and back arc systematically attenuate more than the waves passing through the fore arc. This feature exists for almost every event which is well recorded along the whole array, and indicates that the arc and back arc are characterized by high attenuation. To determine the exact locations of the attenuating regions, we applied a tomographic inversion.

\section{Tomographic Inversion}

\subsection{Method}

[12] We invert the $t^{*}$ measurements for 2-D variations in $1 / Q$. The study region is divided into blocks and each block

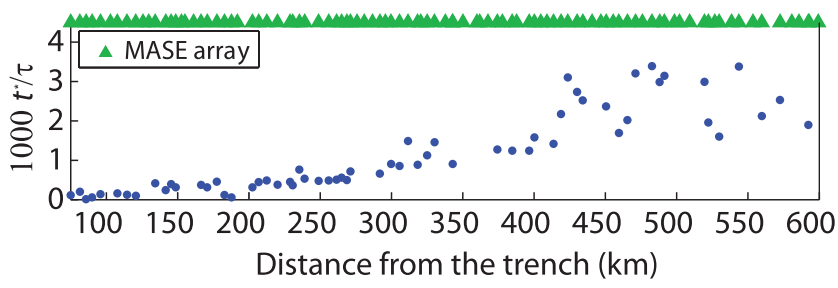

Figure 4. Path-averaged attenuation for rays from one event to each station along MASE array. The event shown here is the same as that in Figure 3. The Path-averaged attenuation parameter $1000 t^{*} / \tau$ is plotted versus the position of each station where the wave is recorded. 


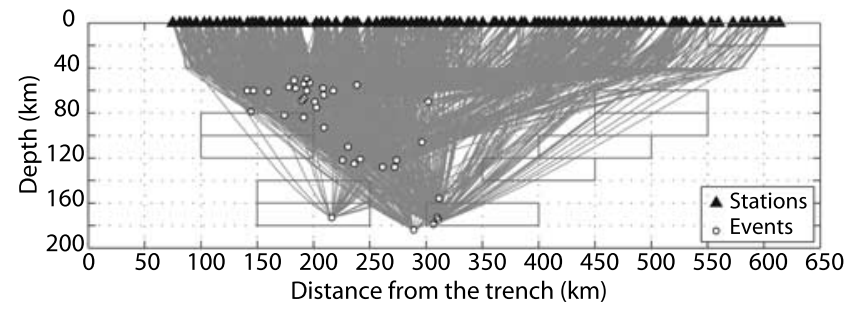

Figure 5. Raypaths and grids used for tomographic inversion. This cross section is perpendicular to the trench and along MASE array as indicated by line $\mathrm{AA}^{\prime}$ in Figure 1. Stations are shown as triangles. Events (open circles) are projected onto this cross section. Rays are traced in IASP91 velocity model with Moho at $40 \mathrm{~km}$ depth [Pérez-Campos et al., 2008]. Block sizes are mostly $50 \mathrm{~km} \times 20 \mathrm{~km}$, with larger blocks $(100 \mathrm{~km} \times 20 \mathrm{~km})$ at edge to increase the robustness. Larger blocks are highlighted by solid lines.

is assumed to have constant $1 / Q$. The observed $t^{*}$ for the $i$ th ray path is

$$
t_{i}^{*}=\sum_{j} \tau_{i j}\left(Q^{-1}\right)_{j}
$$

where $\tau_{i j}$ is the travel time in block $j$ for the $i$ th path, $Q_{j}$ is the quality factor for block $j$. Since $\tau_{i j}$ can be considered to be independent of $\left(Q^{-1}\right)_{j}$, there exists a linear relationship between $t_{i}^{*}$ and $\left(Q^{-1}\right)_{j}$. The inversion problem can be written in matrix form as

$$
[\tau]_{N M}\left[Q^{-1}\right]_{M}=\left[t^{*}\right]_{N}
$$

where $M$ is the number of blocks and $N$ is the number of $t^{*}$ measurements. In this study, a total of 1588 measurements of $t^{*}$ were used.

[13] We assume the attenuation structure has no variation along the strike of the Middle American Trench, and invert for 2-D attenuation structure in the cross section perpendicular to the trench, and along the MASE array (shown as line $\mathrm{AA}^{\prime}$ in Figure 1). On the basis of the ray coverage, we first divided the cross section into blocks with $50 \mathrm{~km}$ horizontal spacing and $20 \mathrm{~km}$ vertical spacing. We then modified some blocks with hit counts less than 8 by combining them with their neighboring blocks to make larger $100 \mathrm{~km} \times 20 \mathrm{~km}$ blocks, thus increasing the robustness at edge. Different model parameterizations were tested, and show overall similar feature of the inversion results. To compute $t_{i j}$, we traced rays in IASP91 velocity model [Kennett and Engdahl, $1991]$ with Moho at $40 \mathrm{~km}$ depth, as indicated by receiver functions [Pérez-Campos et al., 2008] (Figure 5).

[14] A damped least squares method which minimizes a combination of data misfit and model norm was used to solve this problem:

$$
\left[Q^{-1}\right]_{M}=\left([\tau]_{M N}^{T}[\tau]_{N M}+\mu I\right)^{-1}[\tau]_{M N}^{T}\left[t^{*}\right]_{N}
$$

The damping factor $\mu=5$ was selected on the basis of the $\mathrm{L}$ curve criterion [Aster et al., 2005].

\subsection{Inversion Results}

[15] A high-attenuation result in the mantle wedge (Figure 6) is consistent with the study of Singh et al. [2006]. The high attenuation, however, does not prevail in the whole mantle wedge, but is localized in a zone about $80 \mathrm{~km}$ to $120 \mathrm{~km}$ beneath the TMVB, and about $400 \mathrm{~km}$ to $500 \mathrm{~km}$ from the trench. It is about $50 \mathrm{~km}$ away from the top of the slab. The high-attenuation zone in the mantle wedge has $Q_{p}$ less than 200, with the lowest $Q_{p}$ value equals to 130. Because the $Q$ determined in this study is for $\mathrm{P}$ wave, and is frequency independent, it cannot be compared with the upper bound of the frequency-dependent shear wave $Q$ in the mantle wedge estimated by Singh et al. [2006] in a straightforward way. However, taking $Q_{p} / Q_{s}=1.5-2.25$, and frequency-independent $Q$ measurements mostly reflect $Q$ at the upper end of the frequency band [Roth et al., 1999; Stachnik et al., 2004], the $Q$ for the high-attenuation zone in the mantle wedge from our study is significantly lower than the estimate of the upper bound of the attenuation $Q_{s}=120$ $f^{0.75}(0.1 \leq f \leq 10 \mathrm{~Hz})$ by Singh et al. [2006]. Their value is similar to what we find for the corner of the mantle wedge.

[16] Another $\mathrm{P}$ wave high-attenuation zone is imaged in the crust beneath and to the north of the TMVB, which is consistent with studies of $\mathrm{Lg}$ wave attenuation in the same area [Singh et al., 2007]. The high attenuation mostly concentrates in the lower crust, about $300 \mathrm{~km}$ to $600 \mathrm{~km}$

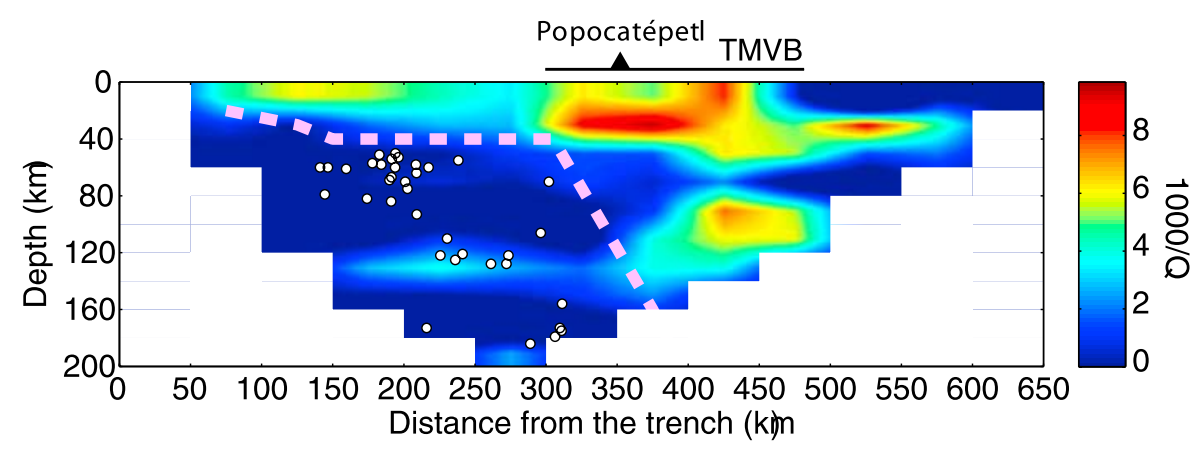

Figure 6. Results for 2-D tomographic inversion in 1000/Q. The TMVB is shown on top as a line for reference, together with Popocatépetl volcano (triangle). Dashed line indicates the top of slab along MASE array, based on receiver functions and velocity tomography studies [Pérez-Campos et al., 2008]. Earthquakes used in this study are shown as white dots. 

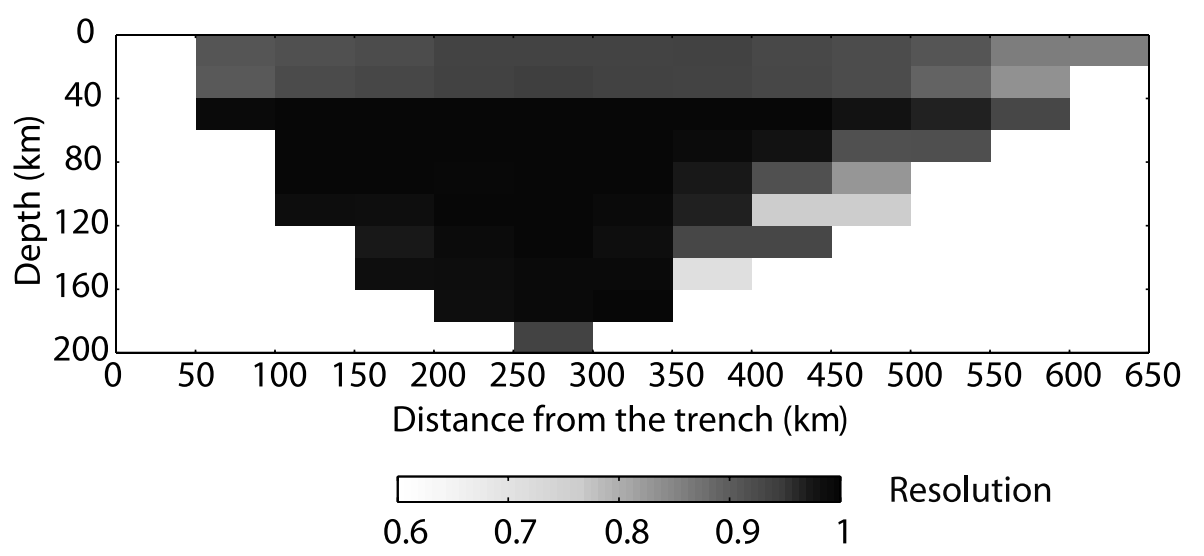

Figure 7. Diagonal elements of the model resolution matrix. The resolution is higher than 0.7 for all the blocks with nonzero hit counts.

from the trench. Two prominent subzones with $Q_{p} \sim 120$ exist in the high-attenuation region in the lower crust. One is beneath the TMVB close to the trench, and the other is to the north of the TMVB. The volcano Popocatépetl lies roughly on the maximum $\left(Q_{p} \sim 110\right)$ of the high-attenuation zone. High attenuation is also found to be diffused in the upper crust in the fore arc and arc, especially at a location about $400 \mathrm{~km}$ to $450 \mathrm{~km}$ from the trench. Low attenuation $\left(Q_{p}>1000\right)$ is imaged in a broad area from the coast to the front of the TMVB, and deeper than $40 \mathrm{~km}$.

\subsection{Resolution}

[17] The resolution of the inversion was evaluated by the model resolution matrix. Diagonal elements of the resolution matrix measure how much information is recovered in each block (Figure 7). Because of the close-spaced stations, most part of the model is well resolved, especially the forearc region deeper than $40 \mathrm{~km}$ (resolution $>0.95$ ). The resolution in the crust is a little lower, because of the limited crossing ray paths, and also because rays travel less through the crust blocks compared with mantle blocks since most events are far away from the stations. The edges of the model are relatively less well resolved, owing to the low ray coverage. It should be noted that since we used relatively large blocks, and combined blocks with hit counts less than 8 to increase the robustness at edges, even the least well resolved block has resolution as high as 0.7 . This means the whole model is generally well resolved.

[18] We also performed numerical tests to examine the robustness for regions of interest in the inversion. In each test, we trace the ray paths through an input $1000 / Q$ model to generate synthetic $t^{*}$ data, and add some normally distributed noise with a standard deviation of 0.02 to the data. Then we invert these $t^{*}$ values for $1000 / Q$ in the same way as we did for real data. In the first test, the input $1000 / Q$ model has high-attenuation anomaly in the lower crust in the arc and back arc (Figure $8 \mathrm{a}$ ). The values of $1000 / Q$ for the anomaly and background are 10 and 1 respectively, both being comparable to the inversion results. The anomaly is shown to be generally recovered, with some smearing into the upper crust (Figure 8b). In the second test, the highattenuation anomaly lies in the mantle wedge between depths of 80 and $120 \mathrm{~km}$, and 400 to $500 \mathrm{~km}$ away from the trench (Figure $8 \mathrm{c}$ ). The test shows that the anomaly can
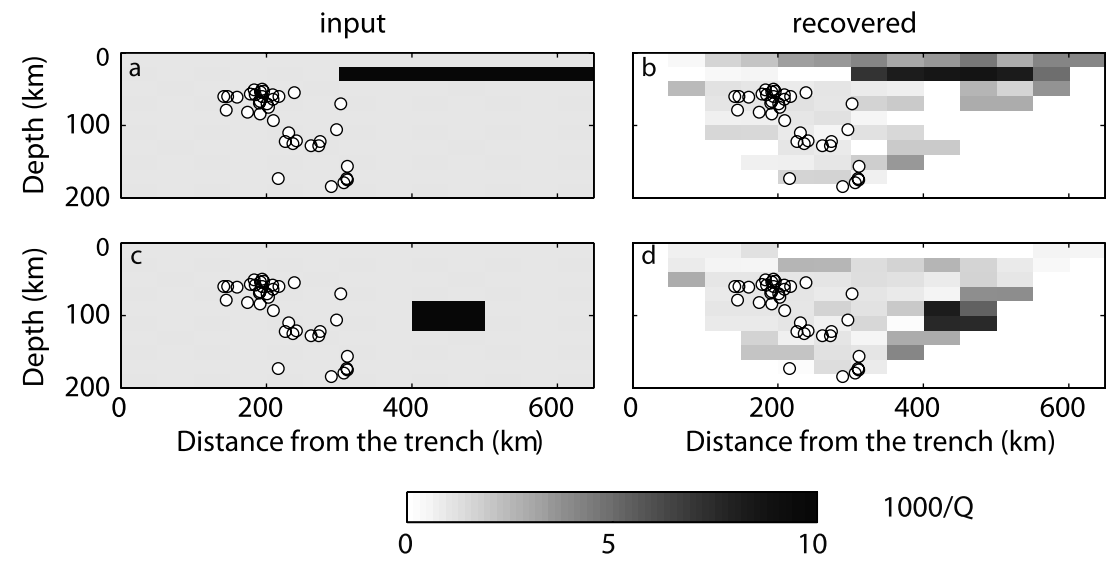

Figure 8. Numerical resolution tests. Figures $8 \mathrm{a}$ and $8 \mathrm{c}$ are input models with anomalies in part of the lower crust and the mantle wedge, respectively. Figures $8 \mathrm{~b}$ and $8 \mathrm{~d}$ are recovered models by inverting the synthetic data with noise. The anomalies are generally well recovered. White dots indicate events used in this study. 

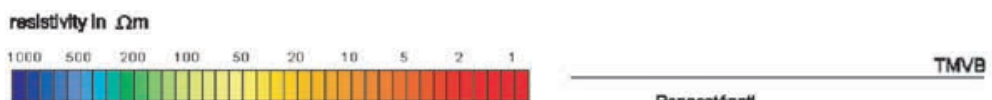

B'

(a)

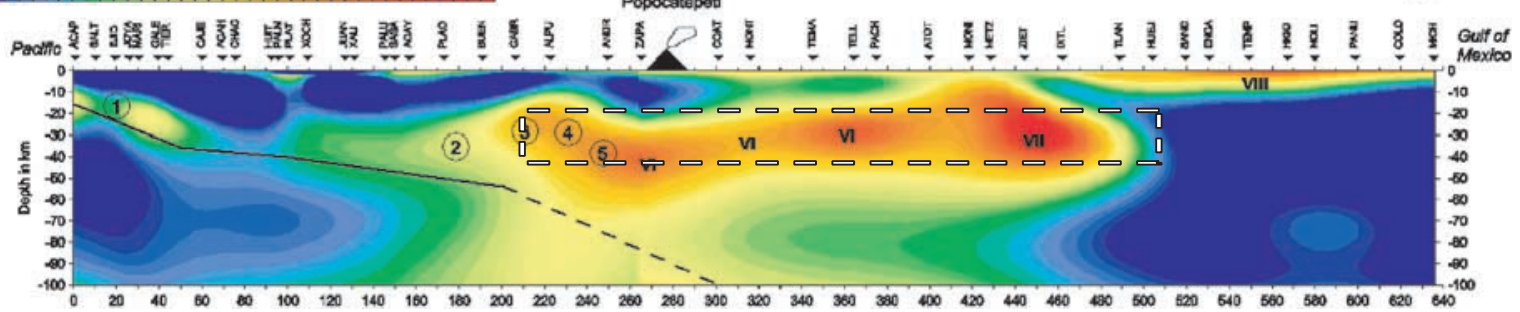

(b)

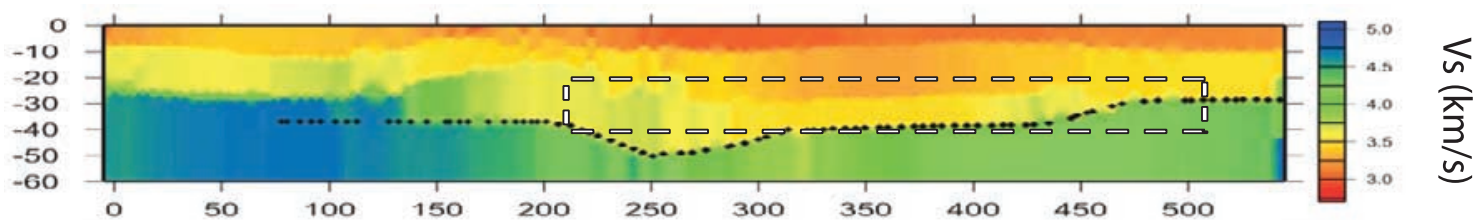

(c)

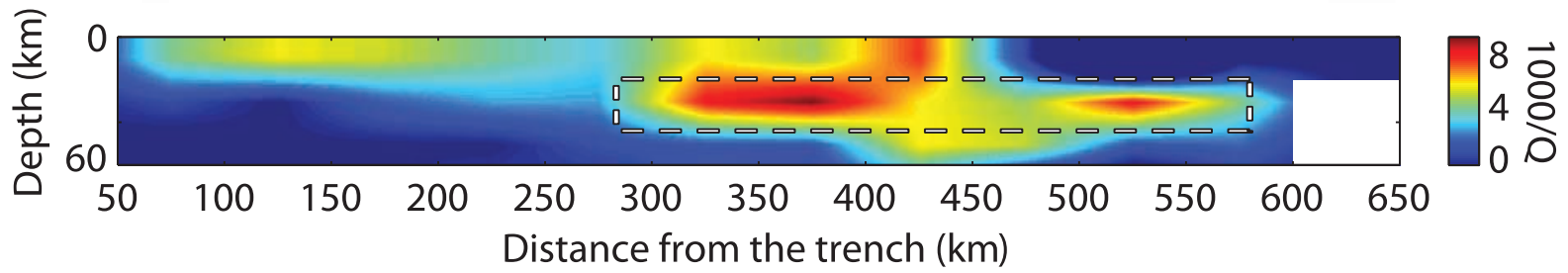

Figure 9. Comparison of different studies. (a) Resistivity results from MT study along almost the same line as MASE array (adapted from Jödicke et al. [2006]). (b) Shear wave velocity along MASE array from surface wave study (adapted from Iglesias et al., submitted manuscript, 2009). (c) Attenuation inversion results from this study (only shallow part of the model is shown). The three plots are lined up. The high-attenuation region in the crust correlates with the low-resistivity and low- $V_{s}$ region (highlighted by dashed boxes).

be generally recovered, although there are also some smearing into nearby blocks (Figure 8d).

\section{Interpretation and Discussions}

[19] The high-attenuation region in the mantle wedge roughly corresponds to a low-velocity region from teleseismic wave studies [Husker and Davis, 2009]. Several factors including temperature, hydration and melt can account for both high attenuation and low velocity [Karato, 2003, and references therein]. Considering the subduction zone setting and the active volcanism above the mantle wedge, high temperature could be a large factor for the imaged high-attenuation zone in the mantle wedge. However, fluids and melts may also play important roles. The small amount of sediment fill in the Middle American Trench suggests that a dominant part of the oceanic sediments are subducted [Manea et al., 2003]. Evidence of the existence of fluids and volatiles in the mantle wedge are also found by geochemical studies [Blatter and Carmichael, 1998; Carmichael, 2002]. As oceanic lithosphere subducts into the mantle, it encounters higher temperature and pressure, and when it reaches certain depths, the water from oceanic crust and sediments is released into the overlying mantle wedge, lowering the melting temperature of peridotite [Peacock, 2003]. The temperature at the top of the slab, however, is usually still not high enough for melting because of the cooling of the slab itself, so the fluids continue to migrate in the mantle wedge. As the temperature rises and finally exceeds the wet solidus of peridotite, partial melts will occur, and they will be away from the top of the slab [Hebert et al., 2009]. Our inversion results are consistent with this process, with the focused high-attenuation zone in the mantle wedge probably indicating a region with partial melts. Because our study is for $\mathrm{P}$ wave, the imaged high-attenuation zone probably only shows where most partial melts are produced, while the whole partial melts zone could be broader, which is expected to be shown in shear wave attenuation as in studies in Nicaragua [Rychert et al., 2008]. The high-attenuation zone in the mantle wedge lies beneath the northern part of the TMVB instead of the southern part where the volcanoes are currently more active, suggesting more complex melt transport rather than simple vertical path. Low attenuation in the corner of the mantle wedge has also been observed in other subduction zones such as Alaska, New Zealand, Nicaragua [Stachnik et al., 2004; Eberhart-Phillips et al., 2008; Rychert et al., 2008]. This feature could be related to the relatively low temperature in the corner of the mantle wedge, which is also dry and isolated from the viscous flow in the mantle wedge [Kincaid and Sacks, 1997; Manea et al., 2005].

[20] The high-attenuation zone in the lower crust beneath and to the north of the TMVB correlates well with lowresistivity zone from MT studies along almost the same line as MASE [Jödicke et al., 2006] (Figure 9a). The contrast of attenuation in the lower crust between the fore arc and other parts is also consistent with shear wave velocity results along the same cross section from surface wave study (A. Iglesias et al., S wave velocity structure below central Mexico using high-resolution surface wave tomography, 
submitted to Journal of Geophysical Research, 2009) (Figure $9 \mathrm{~b}$ ). The high attenuation, low resistivity and low velocity of the lower crust zone beneath and to the north of the TMVB suggest that it might be caused by fluids and partial melts. The flattening of the slab is thought to occur in the Early to Middle Miocene, when the NNW trending Sierra Madre Occidental transited to the EW trending TMVB [Ferrari et al., 1999]. During the Late Miocene, an eastward migrating pulse of mafic volcanism took place in central Mexico, mostly to the north of the TMVB. At 7.56.5 $\mathrm{Ma}$, this mafic pulse reached northern Veracruz state where the northern end of MASE array passes [Ferrari, 2004]. The imaged high-attenuation zone in the crust to the north of the TMVB is probably related to partial melts and metamorphic fluids produced in magmatic events such as the mafic pulse at 7.5-6.5 Ma. The mafic pulse is proposed as a result of eastward propagating slab detachment [Ferrari, 2004]. This slab tear hypothesis is also supported by the current slab image [Pérez-Campos et al., 2008], which suggests that the slab in Guerrero region broke at a depth of $80 \mathrm{~km}$, and undergoes rollback after that [PérezCampos et al., 2008], causing trenchward migrating of the volcanic front [Ferrari et al., 1999]. The imaged highattenuation zone in the crust beneath the TMVB is probably caused by the partial melts related to volcanism for the past $\sim 20 \mathrm{Ma}$. It could also be related to fluids stored in the lower crust, which were released from the oceanic crust and sediment when the slab was flat or shallow below the TMVB during the flattening and rollback periods. The relatively high attenuation in the upper crust could be partly due to the smearing from the lower crust attenuation as shown in Figure $8 b$, and partly due to the presence of fluids or partial melts.

[21] The broad low-attenuation area in the fore arc below $40 \mathrm{~km}$ is likely due to the cold slab. It is artificially broadened because it actually represents a 2-D projection of the slab's 3-D geometry. The 3-D variation of the slab geometry can also been seen from the wide distributed location of the events used (Figure 6).

[22] In this study, inversion was done in a 2-D cross section assuming that the attenuation structure has no variation along the strike of the trench because of the limitations of event-station pairs. However, the slab geometry in this region actually shows noticeable variation as we discussed in section 2. This should be kept in mind when interpreting the inversion results. Since the events used in this study are mostly far away from the MASE line, especially the deep ones, the attenuation image in the mantle wedge does not necessarily represent the structure directly beneath the MASE line, but is biased to the east because of the location of the deeper events. The obtained 2-D attenuation image in this study represents the attenuation structure in this region only in an average sense. Variations of attenuation along the strike of the trench are expected because of variations of tectonic structures. For example, during the data processing, we found that the waves traveling through the west of MASE line generally seem to attenuate more than waves traveling through the east of MASE line, indicating more attenuating crust or uppermost mantle in the west part of the MASE line. However, this may also be due to a bias in average source depth or distance. These effects could not be ruled out with the station geometry of the MASE experiment.

[23] Our attenuation inversion results resemble studies in other subduction zones in the sense that the slab is characterized by low attenuation. However, there are a number of differences in attenuation models for other parts of the subduction system. In southern part of northern Honshu [Tsumura et al., 2000], Alaska [Stachnik et al., 2004], Nicaragua and Costa Rica [Rychert et al., 2008], the highattenuation region mostly lies in the mantle wedge. In contrast, the attenuation model for northern part of northern Honshu [Tsumura et al., 2000] shows high-attenuation region in the crust beneath the volcanic belt. There are also other subduction zones such as central Andes [Schurr et al., 2003] and New Zealand [Eberhart-Phillips et al., 2008], where comparable high-attenuation zones exist both in the mantle wedge and the crust above. The attenuation model for central Mexico seems to belong to this third category. The attenuation structure of the mantle wedge in our model resembles the $\mathrm{P}$ wave attenuation in Nicaragua [Rychert et al., 2008] the most, with the center of the focused highattenuation zone away from the top of the slab.

\section{Conclusions}

[24] We have studied the P wave attenuation structure in central Mexico using the spectral decay method, and obtained a 2-D detailed image of attenuation in this region. The results show a generally low attenuation in the slab. High attenuation is found in both the mantle wedge and the crust. The high-attenuation region in the mantle wedge lies beneath the northern part of the TMVB between the depths of $80 \mathrm{~km}$ and $120 \mathrm{~km}$, with the lowest $Q_{p}$ equals to 130 . The high attenuation is in a compact region away from the top of the subducting slab, and probably indicates where the most partial melts are produced during the subduction process. The high attenuation in the upper plate concentrates mostly in the lower crust. The high-attenuation zone to the north of the TMVB is likely to be related to extinct volcanoes. The high-attenuation zone in the crust beneath the TMVB is probably due to volcanism related partial melts and fluids produced through dehydration process when the slab was undergoing flattening and rollback.

[25] Acknowledgments. This study was supported by the Gordon and Betty Moore Foundation through the Tectonics Observatory at Caltech and NSF grant EAR0609707. Contribution 91 from the Caltech Tectonics Observatory. The ray tracing was done using the package developed by William Menke. We thank Donna Eberhart-Phillips for the $t^{*}$ code. We thank two anonymous reviewers for their constructive comments that helped to improve the manuscript.

\section{References}

Anderson, J. G., and S. E. Hough (1984), A model for the shape of the Fourier amplitude spectrum of acceleration at high frequencies, Bull. Seismol. Soc. Am., 74, 1969-1993.

Aster, R., B. Borchers, and C. H. Thurber (2005), Parameter Estimation and Inverse Problems, Academic, New York.

Blatter, D. L., and I. Carmichael (1998), Hornblende peridotite xenoliths from central Mexico reveal the highly oxidized nature of subarc upper mantle, Geology, 26(11), 1035-1038.

Brune, J. N. (1970), Tectonic stress and spectra of seismic shear waves from earthquakes, J. Geophys. Res., 75(26), 4997-5009.

Carmichael, I. (2002), The andesite aqueduct: Perspectives on the evolution of intermediate magmatism in west-central $\left(105^{\circ}-99^{\circ} \mathrm{W}\right)$ Mexico, Contrib. Mineral. Petrol., 143, 641-663. 
Castro, R. R., J. G. Anderson, and S. K. Singh (1990), Site response, attenuation and source spectra of S-waves along the Guerrero, Mexico, subduction zone, Bull. Seismol. Soc. Am., 80, 1481-1503.

DeMets, C., R. G. Gordon, D. F. Argus, and S. Stein (1994), Effect of recent revisions to the geomagnetic reversal time-scale on estimates of current plate motions, Geophys. Res. Lett., 21, 2191-2194.

Eberhart-Phillips, D., and M. Chadwick (2002), Three-dimensional attenuation model of the shallow Hikurangi subduction zone in the Raukumara Peninsula, New Zealand, J. Geophys. Res., 107(B2), 2033, doi:10.1029/ 2000JB000046.

Eberhart-Phillips, D., M. Reyners, M. Chadwick, and G. Stuart (2008), Three-dimensional attenuation structure of the Hikurangi subduction zone in the central North Island, New Zealand, Geophys. J. Int., 174, 418-434, doi:10.1111/j.1365-246X.2008.03816.x.

Ferrari, L. (2004), Slab detachment control on mafic volcanic pulse and mantle heterogeneity in central Mexico, Geology, 32(1), 77-80.

Ferrari, L., M. Lopez-Martinez, G. Aguirre-Diaz, and G. Carrasco-Nunez (1999), Space-time patterns of Cenozoic arc volcanism in central Mexico: From the Sierra Madre Occidental to the Mexican Volcanic Belt, Geology, 27(4), 303-306.

García, D., S. K. Singh, M. Herráiz, J. F. Pacheco, and M. Ordaz (2004), Inslab earthquakes of central Mexico: $Q$, source spectra, and stress drop, Bull. Seismol. Soc. Am., 94(3), 789-802.

Gómez-Tuena, A., M. T. Orozco-Esquivel, and L. Ferrari (2007), Igneous petrogenesis of the Trans-Mexican Volcanic Belt, in Geology of Mexico, edited by S. A. Alaniz-Álvarez and A. F. Nieto-Samaniego, Spec. Pap. Geol. Soc. Am., 442, 129-181.

Haskov, J., and L. Ottemöller (1999), SEISAN earthquake analysis software, Seismol. Res. Lett., 70, 532-534.

Hebert, L. B., P. Antoshechkina, P. Asimow, and M. Gurnis (2009), Emergence of a low-viscosity channel through the coupling of flow and thermodynamics in a subduction zone, Earth Planet. Sci. Lett., 278, 243-256, doi:10.1016/j.eps1.2008.12.013.

Husker, A., and P. M. Davis (2009), Tomography and thermal state of the Cocos plate subduction beneath Mexico City, J. Geophys. Res., 114 B04306, doi:10.1029/2008JB006039.

Jackson, I., M. S. Paterson, and J. D. Fitz Gerald (1992), Seismic wave dispersion and attenuation in Aheim dunite, Geophys. J. Int., 108, $517-534$

Jödicke, H., A. Jording, L. Ferrari, J. Arzate, K. Mezger, and L. Rüpke (2006), Fluid release from the subducted Cocos plate and partial melting of the crust deduced from magnetotelluric studies in southern Mexico: Implications for the generation of volcanism and subduction dynamics, J. Geophys. Res., 111, B08102, doi:10.1029/2005JB003739.

Karato, S. (2003), Mapping water content in upper mantle, in Inside the Subduction Factory, Geophys. Monogr. Ser., vol. 138, edited by J. Eiler, pp. 135-152, AGU, Washington, D. C

Kennett, B. L. N., and E. R. Engdahl (1991), Travel times for global earthquake location and phase association, Geophys. J. Int., 105, 429-465.

Kincaid, C., and I. S. Sacks (1997), Thermal and dynamical evolution of the upper mantle in subduction zones, J. Geophys. Res., 102, $12,295-12,315$

Macías, J. L. (2007), Geology and eruptive history of some active, volcanoes of Mexico, in Geology of Mexico, edited by S. A. Alaniz-Álvarez and A. F. Nieto-Samaniego, Spec. Pap. Geol. Soc. Am., 442, 183-232.
Manea, M., V. C. Manea, and V. Kostoglodov (2003), Sediment fill in the Middle America Trench inferred from the gravity anomalies, Geofis. Int., 42(4), 603-612.

Manea, V. C., M. Manea, V. Kostoglodov, and G. Sewell (2005), Thermomechanical model of the mantle wedge in central Mexican subduction zone and a blob tracing approach for the magma transport, Phys. Earth Planet. Inter, 149, 165-186.

Mavko, G. M. (1980), Velocity and attenuation in partially molten rocks, J. Geophys. Res., 85, 5173-5189.

Ordaz, M., and S. K. Singh (1992), Source spectra and spectral attenuation of seismic waves from Mexican earthquakes, and evidence of amplification in the hill zone of Mexico City, Bull. Seismol. Soc. Am., 82, 24-43.

Pardo, M., and G. Suárez (1995), Shape of the subducted Rivera and Cocos plates in southern Mexico: Seismic and tectonic implications, J. Geophys. Res., 100(B7), 12,357-12,373.

Park, J., C. R. Lindberg, and F. L. Vernon (1987), Multitaper spectralanalysis of high-frequency seismograms, J. Geophys. Res., 92(B12), $12,675-12,684$

Peacock, S. M. (2003), Thermal structure and metamorphic evolution of subduction slabs, in Inside the Subduction Factory, Geophys. Monogr. Ser., vol. 138, edited by J. Eiler, pp. 7-22, AGU, Washington, D. C.

Pérez-Campos, X., Y. Kim, A. Husker, P. M. Davis, R. W. Clayton, A. Iglesias, J. F. Pacheco, S. K. Singh, V. C. Manea, and M. Gurnis (2008), Horizontal subduction and truncation of the Cocos Plate beneath central Mexico, Geophys. Res. Lett., 35, L18303, doi:10.1029/ 2008 GL035127.

Roth, E. G., D. A. Wiens, L. M. Dorman, J. Hildebrand, and S. C. Webb (1999), Seismic attenuation tomography of the Tonga-Fiji region using phase pair methods, J. Geophys. Res., 104(B3), 4795-4809.

Rychert, C. A., K. M. Fischer, G. A. Abers, T. Plank, E. Syracuse, J. M. Protti, V. Gonzalez, and W. Strauch (2008), Strong along-arc variations in attenuation in the mantle wedge beneath Costa Rica and Nicaragua, Geochem. Geophys. Geosyst., 9, Q10S10, doi:10.1029/ 2008GC002040

Schurr, B., G. Asch, A. Rietbrock, R. Trumbull, and C. Haberland (2003), Complex patterns of fluid and melt transport in the central Andean subduction zone revealed by attenuation tomography, Earth Planet. Sci. Lett., 215(1-2), 105-119.

Singh, S. K., J. F. Pacheco, D. García, and A. Iglesias (2006), An estimate of shear-wave $O$ of the mantle wedge in Mexico, Bull. Seismol. Soc. Am., 96(1), 176-187.

Singh, S. K., A. Iglesias, D. Garcia, J. F. Pacheco, and M. Ordaz (2007), $Q$ of $\mathrm{Lg}$ waves in the central Mexican Volcanic Belt, Bull. Seismol. Soc. Am., 97, 1259-1266.

Stachnik, J. C., G. A. Abers, and D. H. Christensen (2004), Seismic attenuation and mantle wedge temperatures in the Alaska subduction zone, J. Geophys. Res., 109, B10304, doi:10.1029/2004JB003018.

Tsumura, N., S. Matsumoto, S. Horiuchi, and A. Hasegawa (2000), Three-dimensional attenuation structure beneath the northeastern Japan arc estimated from spectra of small earthquakes, Tectonophysics, $319(4), 241-260$

T. Chen and R. W. Clayton, Seismological Laboratory, California Institute of Technology, MC 252-21, Pasadena, CA 91125, USA. (tchen@gps.caltech.edu; clay@gps.caltech.edu) 